Article

\title{
FT-IR Characterization of Antimicrobial Hybrid Materials through Sol-Gel Synthesis
}

\author{
Michelina Catauro $^{1, *} \mathbb{D}$, Simona Piccolella ${ }^{2}\left[\right.$ and Cristina Leonelli ${ }^{3}[\mathbb{C}$ \\ 1 Department of Engineering, University of Campania “Luigi Vanvitelli”, Via Roma 29, 81031 Aversa, Italy \\ 2 Department of Environmental, Biological and Pharmaceutical Sciences and Technologies, University of \\ Campania “Luigi Vanvitelli", Via Vivaldi 43, I-81100 Caserta, Italy; simona.piccolella@unicampania.it \\ 3 Department of Engineering “Enzo Ferrari”, University of Modena and Reggio Emilia, Via P. Vivarelli n. 10, \\ 41125 Modena, Italy; cristina.leonelli@unimore.it \\ * Correspondence: michelina.catauro@unicampania.it
}

Received: 5 January 2020; Accepted: 6 February 2020; Published: 10 February 2020

check for updates

\begin{abstract}
Silica/polycaprolactone and titania/polycaprolactone hybrid organic/inorganic amorphous composites were prepared via a sol-gel method starting from a multi-element solution containing tetramethyl orthosilicate (TMOS) or titanium butoxide (TBT), polycaprolactone (PCL), water and methylethylketone (MEK). The molecular structure of the crosslinked network was based on the presence of the hydrogen bonds between organic/inorganic elements as confirmed by Fourier Transform Infra-Red (FT-IR) analysis. In particular, the structure of crosslinked network was realized by hydrogen bonds between the $\mathrm{X}-\mathrm{OH}(\mathrm{X}=\mathrm{Si}$ or $\mathrm{Ti})$ group ( $\mathrm{H}$ donator) in the sol-gel intermediate species and ester groups (H-acceptors) in the repeating units of the polymer. The morphology of the hybrid materials; pore size distribution, elemental homogeneity and surface features, was studied by scanning electron microscopy/energy dispersive spectroscopy (SEM/EDS) and by atomic force microscopy (AFM). The bioactivity of the synthesized hybrid materials was confirmed by observing the formation of a layer of hydroxyapatite (HAP) on the surface of the samples soaked in a simulated body fluid. The antimicrobial behavior of synthetized hybrids was also assessed against Escherichia coli bacteria. In conclusion, the prepared hybrid materials are proposed for use as future bone implants.
\end{abstract}

Keywords: hybrid composite; $\mathrm{PCL} ; \mathrm{TiO}_{2} ; \mathrm{SiO}_{2} ; \mathrm{FT}-\mathrm{IR}$ spectroscopy; antibacterial behavior

\section{Introduction}

Since the 1990s, organic/inorganic nanocomposites networks have become a growing field of investigation [1-3]. The sol-gel route represents an interesting approach, which can be effectively applied to the preparation of the inorganic phases within the inorganic/organic hybrid materials, due to the fact that it can occur in liquid solutions at room temperature. These materials are considered to be biphasic, where the organic and inorganic phases are mixed at the nanometric or submicronic scales. The smaller the scale of mixing, the more unexpected the properties are, since these materials may show properties that are not the sum of the individual contributions from both phases. Additionally, it has been proved that the role of the inner interfaces is predominant; in particular, the nature of the interface is the critical parameter used to distinguish two different classes [4]: class I collects those hybrid materials with weak bonds (hydrogen, van der Waals or ionic bonds), and class II gathers materials where the phases are linked together through strong chemical bonds (covalent or ionic-covalent bonds). In class I, materials, obtained combining the sol-gel process with polymer chemistry, can be enclosed with a large number of different applications [5-7], from non-linear optical materials [8] to mesoporous materials [9]. 
The basic chemical reactions of the sol-gel process are the hydrolyses of metal alkoxides in the proper solvent, usually an alcohol/water mixture, followed by their polycondensation. In the first stage, substituting the alkoxide groups (OR) with the hydroxyl groups $(\mathrm{OH})$ in the metal alkoxide offers a large number of opportunities, due to the presence of such reactive $\mathrm{OH}$ groups, to match with organic monomers. Thus, a variety of organic polymers have been introduced into inorganic networks. The final material derives from the condensation of two $\mathrm{OH}$ groups with the elimination of a water molecule. The two adjacent $\mathrm{OH}$ groups may belong to one organic and one inorganic monomer to afford the formation of a hybrid or composite material with covalent bonds between the polymer and inorganic elements. The gel reaction might also give rise to weaker bonds, such as a hydrogen bond, in the organic/inorganic hybrid bulky materials. It is well known that many parameters, such as type and concentration of reactants, solvents, catalysts, reaction temperature and removal rate of by-products and solvents, influence the sol-gel process $[10,11]$. Hence, it is evident that the presence of organic elements modifies the morphology and physical properties of the final sol-gel products. The difference in products that are obtained through the base-catalyzed sol-gel reaction and through the carefully controlled acid-catalyzed one is evident, since from the first process, translucent or opaque products with visible organic/inorganic phase separation are obtained, while from the second, transparent and monolithic materials are realized. A key topic that is persistently challenging in these organic-altered materials is the degree of mixing of the organic/inorganic elements, i.e., the phase homogeneity. The high optical transparency to visible light suggests that the organic/inorganic phase separation, if any, occurs on a scale of $\leq 400 \mathrm{~nm}$ [12]. Two of the most-used techniques to investigate phase mixing in hybrid materials, at micrometric scale, are atomic force microscopy (AFM) [13] and scanning electron microscopy (SEM).

In this work, we propose a combination of bioactive organic and inorganic phases to obtain a single and homogeneous hybrid composite using the sol-gel route for the inorganic three-dimensional (3D) network. In particular, we chose $\mathrm{SiO}_{2}$ and $\mathrm{TiO}_{2}$-containing bioactive materials that are often produced in the amorphous state, typical of glasses, via the sol-gel route. Both of these oxides are known to bond to living bone [14]. Thus, a hybrid material based on smart combinations of biodegradable polymers, specifically polycaprolactone (PCL), and such bioactive inorganic compounds is of particular interest, since it exhibits tailored physical, biological and mechanical properties, as well as predictable degradation behavior.

The purpose of this manuscript is the microstructural characterization and bioactivity assessment of polycaprolactone $/ \mathrm{SiO}_{2}$ and polycaprolactone $/ \mathrm{TiO}_{2}$ hybrid materials prepared by the sol-gel process. These materials were tested in simulated body fluid (SBF) to prove their bioactivity in vitro [15] since the organic element, PCL, was preferred due to its biodegradable and biocompatible nature. Furthermore, as implant failure is often a consequence of microbial infections that occur in spite of antimicrobial prophylaxis and aseptic working conditions, the antimicrobial capability of the synthetized hybrids was investigated through a diffusion method against Gram-positive Escherichia coli after $24 \mathrm{~h}$ of incubation.

\section{Materials and Methods}

Organic/inorganic hybrid materials $\mathrm{MO}_{2} / \mathrm{PCL}$ with $\mathrm{M}=\mathrm{Si}$ or Ti were prepared, using the sol-gel process, from polycaprolactone of analytical reagent grade as the organic element, and tetramethyl orthosilicate (TMOS) as the source for $\mathrm{SiO}_{2}$, or titanium butoxide as the source for $\mathrm{TiO}_{2}$. The amount of the organic element was 6 wt. $\%$ in both $\mathrm{PCL} / \mathrm{SiO}_{2}$ and $\mathrm{PCL} / \mathrm{TiO}_{2}$ hybrid materials, as optimized in a previous work [15].

In Figure 1, the flow chart of hybrid synthesis by the applied sol-gel route is depicted.

The presence of hydrogen bonds between organic/inorganic elements of the hybrid materials was unraveled by acquiring their FT-IR spectra in the $400-4000 \mathrm{~cm}^{-1}$ region using a Prestige 21 (Shimadzu, Kyoto, Japan) system with a resolution of $4 \mathrm{~cm}^{-1}$ (45 scans). The spectrometer used a Deuterated Triglycine Sulfate (DTGS) detector with $\mathrm{KBr}$ windows. Disks with a diameter of $13 \mathrm{~mm}$, a thickness of $2 \mathrm{~mm}$, a weight of $200 \mathrm{mg}$ and containing $1 \mathrm{wt} . \%$ of sample in $\mathrm{KBr}$ were obtained by pressing sample 
powders into a cylindrical holder using a Specac manual hydraulic press. The Prestige software (IR solution) was used to analyze the FT-IR spectra.

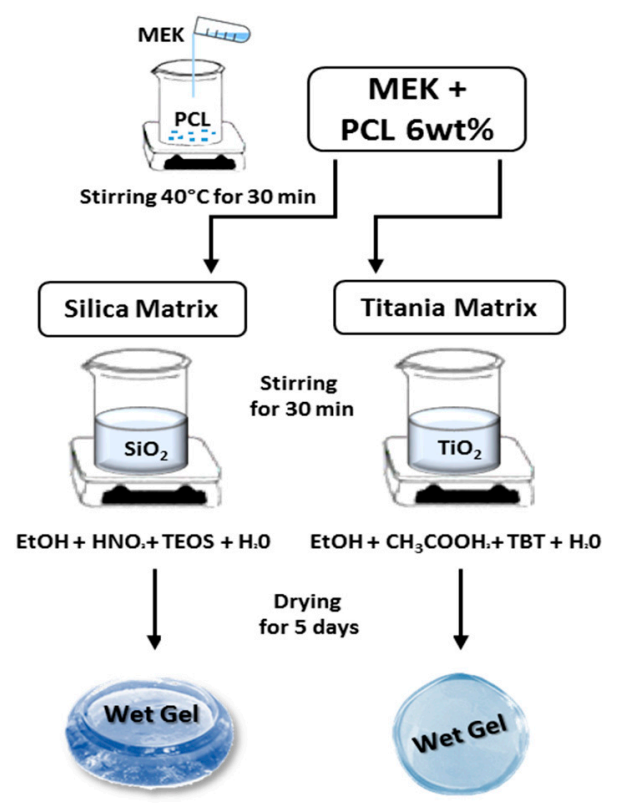

Figure 1. Flow chart of $\mathrm{PCL} / \mathrm{SiO}_{2}$ and $\mathrm{PCL} / \mathrm{TiO}_{2}$ gel synthesis.

The nature of $\mathrm{MO}_{2}$ gel, $\mathrm{PCL}$ and $\mathrm{PCL} / \mathrm{MO}_{2}$ hybrid materials was confirmed by X-ray diffraction (XRD) analysis using a Philips diffractometer. Powder samples were scanned from $2 \Theta=5^{\circ}$ to $60^{\circ}$ using $\mathrm{CuK}_{\alpha}$ radiation.

The surface morphology and phase distribution of the organic/inorganic hybrid materials were investigated by a scanning electron microscope (Cambridge model S-240) and by an atomic force microscope (Digital Instruments Multimode) in contact mode in air. For SEM, the specimens were previously coated with a thin Au film to obtain a conductive surface.

Bioactivity tests were performed on pieces of the hybrid materials soaked in a simulated body fluid (SBF) with the proper ion concentrations $[16,17]$ nearly equal to those of human blood plasma. During soaking, the temperature was fixed at $37^{\circ} \mathrm{C}$ and the ratio between the exposed surface and the volume solution was kept constant $\left(50 \mathrm{~mm}^{2} \mathrm{~mL}^{-1}\right.$ of solution), due to its strong influence on the reactivity degree, as previously reported [17-19].

The ability of the hybrid materials to form an apatite layer during the SBF soaking test was ascertained by FT-IR analysis on $\mathrm{SiO}_{2} / \mathrm{PCL}$-reacted samples, where SEM and EDS analyses were performed on $\mathrm{TiO}_{2} / \mathrm{PCL}$-reacted samples. An SEM outfitted with an energy-dispersive X-ray fluorescence system (EDS, Link AN10000, Oxford Microanalysis) was used to investigate the morphology of the coated sample and to complete it with qualitative elemental analysis.

The antimicrobial activity of synthetized materials was investigated by a diffusion method. Escherichia coli (ATCC 25,922) bacteria culture was diluted in distilled water to achieve a $1.0 \times 10^{6} \mathrm{CFU} / \mathrm{mL}$ suspension. This latter was inoculated in Tryptone Bile Glucuronide Agar (TBX) medium (Liofilchem, Roseto degli Abruzzi (TE), Italy). Sample hybrids and a control disk were placed at the center of the Petri dishes using a pair of sterile tweezers. Incubation was carried out for $24 \mathrm{~h}$ in an incubator at $44^{\circ} \mathrm{C}$. The microbial growth was evaluated by observing the diameter of the inhibition halo (ID). Antimicrobial tests were performed in quadruplicate on different days to ensure reproducibility, and values are expressed as the mean values \pm standard deviation (SD) of all the performed measurements. 


\section{Results and Discussion}

Gelation is the result of hydrolysis and condensation according to the following reactions, where $\mathrm{M}=\mathrm{Si}$ and $\mathrm{R}=\mathrm{CH}_{3}$ for $\mathrm{PCL} / \mathrm{SiO}_{2} ;$ and $\mathrm{M}=\mathrm{Ti}$ and $\mathrm{R}=\mathrm{C}_{4} \mathrm{H}_{9}$ for $\mathrm{PCL} / \mathrm{TiO}_{2}$.

$$
\begin{gathered}
\mathrm{M}(\mathrm{OR})_{4}+\mathrm{nH}_{2} \mathrm{O} \rightarrow \mathrm{M}(\mathrm{OR})_{4-\mathrm{n}}(\mathrm{OH})_{\mathrm{n}}+\mathrm{nROH} \\
-\mathrm{MOH}+\mathrm{RO}-\mathrm{M}-\rightarrow-\mathrm{M}-\mathrm{O}-\mathrm{M}-+\mathrm{ROH} \\
-\mathrm{M}-\mathrm{OH}+\mathrm{OH}-\mathrm{M} \rightarrow-\mathrm{M}-\mathrm{O}-\mathrm{M}-+\mathrm{H}_{2} \mathrm{O}
\end{gathered}
$$

The reaction mechanism is not known in great detail; however, it is generally accepted that it proceeds through a second-order nucleophilic substitution [19]. The reaction (4) shows the formation of the organic/inorganic network in which a hydrogen bond between the ester $\mathrm{C}=\mathrm{O}$ group of the organic polymer and the inorganic matrix was supposed to occur. Indeed, the carbonyl group of the polymer chain acts as an $\mathrm{H}$-acceptor, whereas the $\mathrm{O}-\mathrm{H}$ group of the inorganic matrix is the $\mathrm{H}$-donor.

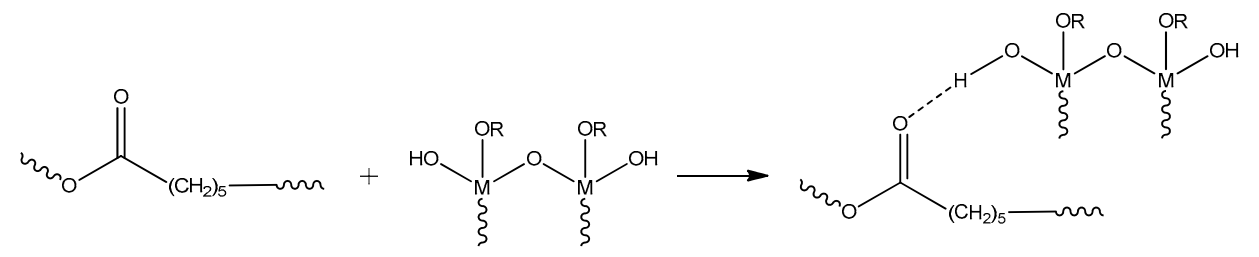

In Figure 2, FT-IR spectra of pure PCL and $\mathrm{SiO}_{2}$ are reported, together with the one recorded for $\mathrm{SiO}_{2} / \mathrm{PCL}_{6}$ wt.\% gel in order to highlight spectral differences due to the interaction of the two phases. The PCL spectrum (Figure 2a) shows the asymmetric and symmetric stretching of polymer $-\mathrm{CH}_{2}-$ groups, corresponding to the bands at 2945 and $2866 \mathrm{~cm}^{-1}$, respectively, and two peaks at $1470 \mathrm{~cm}^{-1}$ and $1360 \mathrm{~cm}^{-1}$ related to their bending modes. The sharp and strong band at $1730 \mathrm{~cm}^{-1}$ referred to the $\mathrm{C}=\mathrm{O}$ stretching vibration. On the other hand, the hybrid's FT-IR spectrum (Figure $2 b$ ) showed a broad band in the range $3600-3200 \mathrm{~cm}^{-1}$, the intensity of which almost completely covered the characteristic peaks of PCL methylene stretching. According to previous work, this referred to un-free $\mathrm{O}-\mathrm{H}$ groups and could be explained considering the establishment of hydrogen bonds between the carbonyl groups of the polymer chains and the inorganic part [11]. The shift of the pure PCL signal at $1730 \mathrm{~cm}^{-1}$ to lower wavenumbers $\left(1720 \mathrm{~cm}^{-1}\right)$ seemed to corroborate this hypothesis. Moreover, both in $\mathrm{SiO}_{2} / \mathrm{PCL}_{6} \mathrm{wt} . \%$ and $\mathrm{SiO}_{2}$ gel spectra (Figure $2 \mathrm{~b}, \mathrm{c}$ ), the bands at 1080 and $460 \mathrm{~cm}^{-1}$, corresponding to the stretching and bending modes of $\mathrm{SiO}_{2}$ tetrahedra [20], were marked, as expected. This evidence indicates that the presence of the PLC in the hybrid composites does not inhibit the reticulation of the Si-O-Si 3D network.

In Figure 3, the infrared spectrum of PCL, as discussed above, was compared to those recorded for the $\mathrm{TiO} 2+\mathrm{PCL}_{6}$ wt.\% gel and the $\mathrm{TiO} 2$ gel. The signals detectable for the latter were the typical bands already described elsewhere [3]. In the hybrid's spectrum (Figure 3b), the broad and strong band in the region $3400-3200 \mathrm{~cm}^{-1}$, due to $-\mathrm{OH}$ vibrations, obscured almost completely the polycaprolactone $\mathrm{CH} 2$ asymmetric and symmetric stretching modes (at 2945 and $2866 \mathrm{~cm}^{-1}$, respectively). In addition, the band at $1715 \mathrm{~cm}^{-1}$, attributable to the PCL ester bond, which shifted to low wavenumbers following the synthetic route, was not particularly evident. The scarce intensity could depend on the low amount of the polymer in the synthetized material. Furthermore, other signals typical of acetic-acid-containing titania sol-gel materials were detected. Indeed, the doublet at 1530 and $1445 \mathrm{~cm}^{-1}$ likely corresponded to the asymmetric and symmetric stretching vibrations of the carboxylic group coordinated to $\mathrm{Ti}$ as a bidentate ligand. The band around $800 \mathrm{~cm}^{-1}$ correlates with the vibrations of polyhedral TiOn with a coordination number less than 6 . 


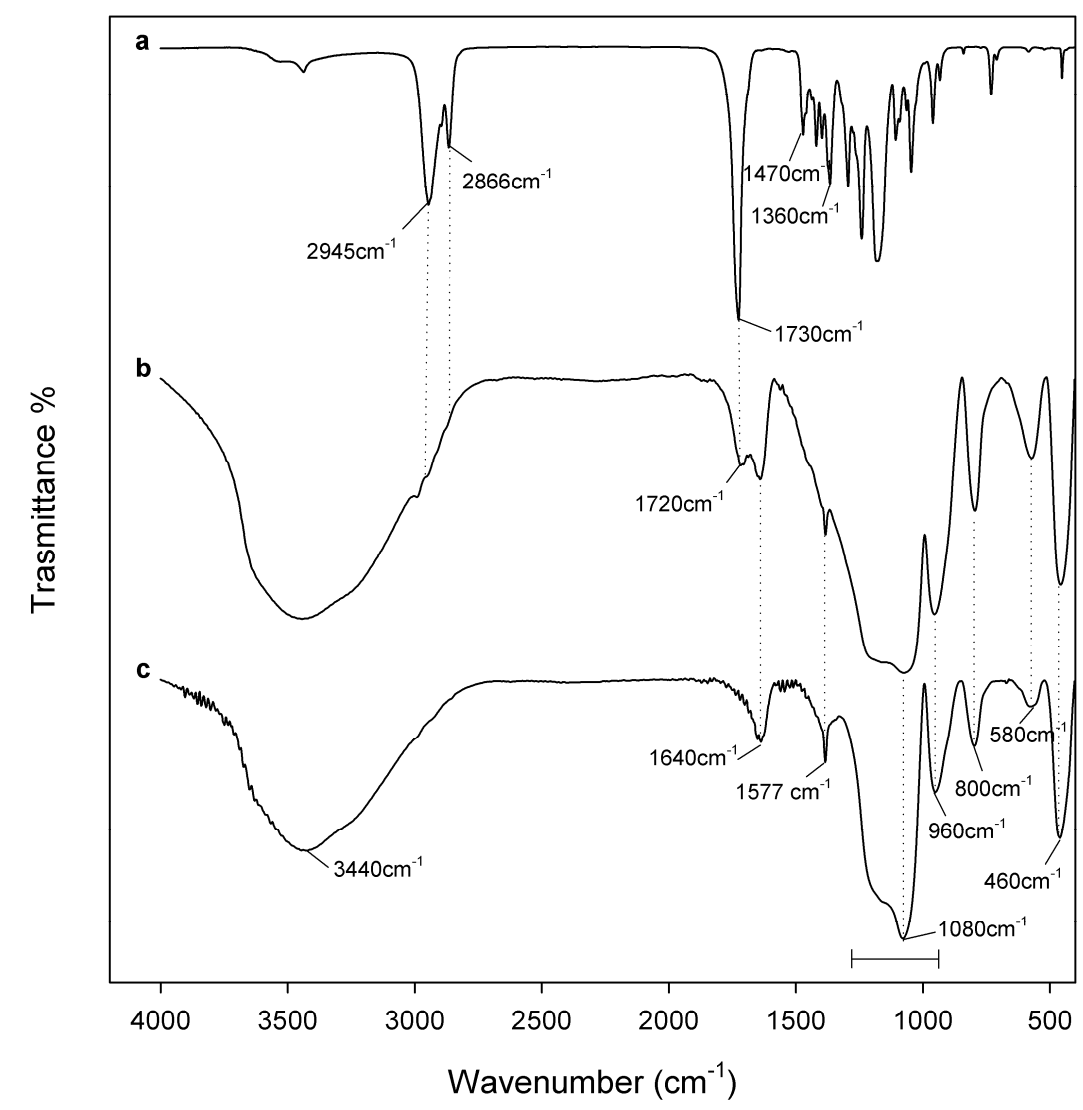

Figure 2. FT-IR spectra of (a) PCL, (b) $\mathrm{SiO}_{2}+\mathrm{PCL}_{6}$ wt.\% gel and (c) $\mathrm{SiO}_{2}$ gel.

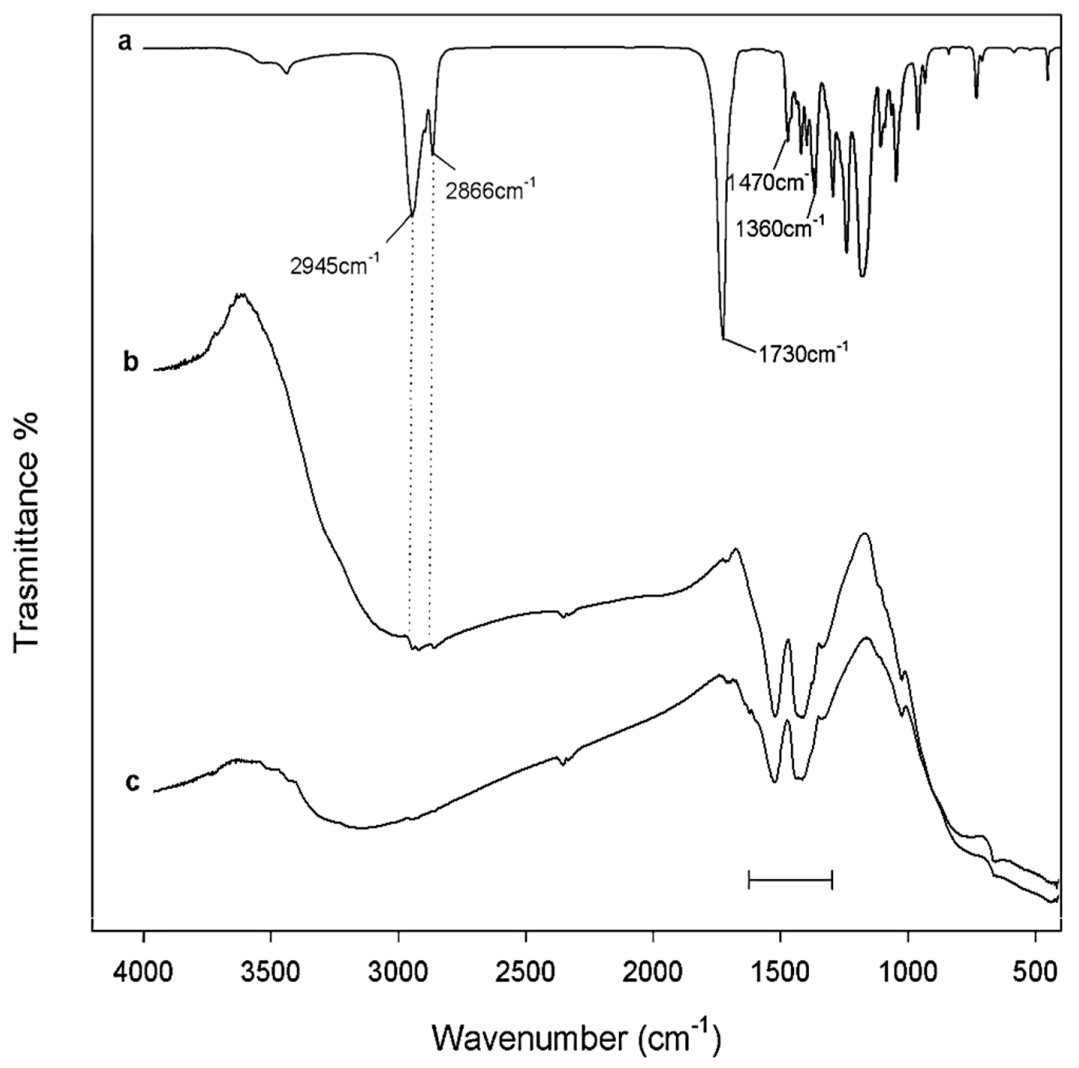

Figure 3. FT-IR spectra of (a) PCL, (b) $\mathrm{TiO}_{2}+\mathrm{PCL}_{6}$ wt. $\%$ gel and (c) $\mathrm{TiO}_{2}$ gel. 
The nature and microstructure of the $\mathrm{SiO}_{2} / \mathrm{PCL}$ and $\mathrm{TiO}_{2} / \mathrm{PCL}$ hybrid materials were investigated by X-ray diffraction (XRD) and scanning electron microscopy (SEM). In particular, based on the acquired diffractograms, hybrids exhibit amorphous features as their metal oxide precursors. In fact, taking into account Figure 4, it is observable that sharp peaks, typical of a crystalline material, can be detected on the diffractogram of pure polycaprolactone (Figure 4a), whereas the $\mathrm{TiO}_{2}$ gel exhibits broad humps characteristic of amorphous materials (Figure $4 \mathrm{~b}$ ). On the other hand, the XRD spectrum of the $\mathrm{TiO}_{2} / \mathrm{PCL}$ hybrid material gel was in line with an amorphous material, such as $\mathrm{TiO}_{2}$ gel (Figure 4c).

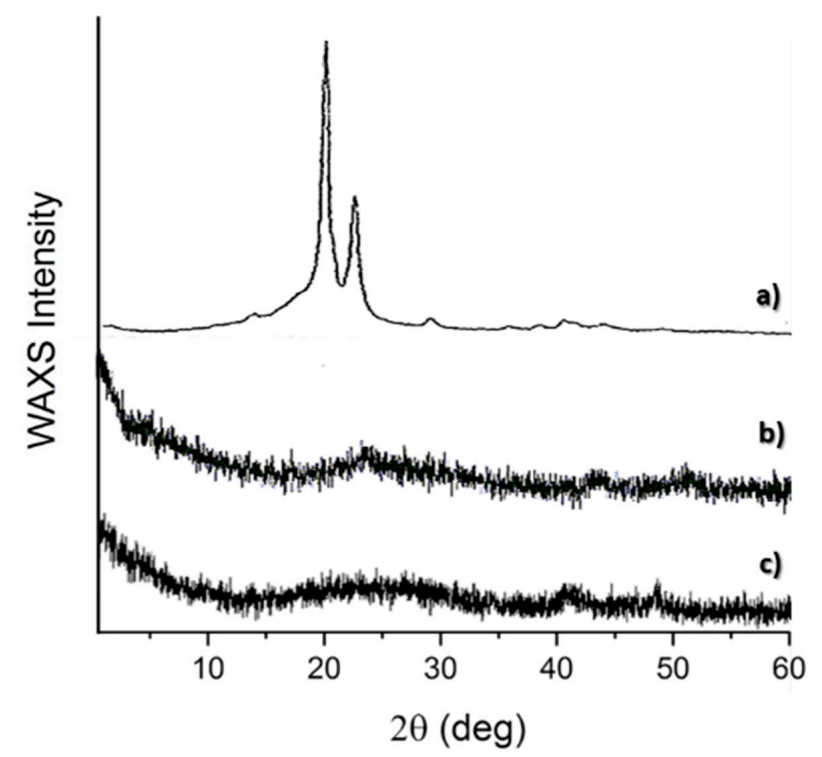

Figure 4. XRD spectra of (a) PCL, (b) $\mathrm{TiO}_{2}$ gel and (c) $\mathrm{TiO}_{2} / \mathrm{PCL}$ gel.

SEM micrographs of $\mathrm{TiO}_{2}$ gel and $\mathrm{TiO}_{2} / \mathrm{PCL}$ gel samples, reported in Figure 5, evidence a more homogenous morphology for the first one, as expected. With the introduction of the organic phase (Figure 5b), the unstructured $\mathrm{TiO}_{2}$ gel presents a micrometric feature. Neither of the two morphologies, though, exhibit a regular geometric morphology indicating crystalline structures or phase separation. This result confirms the XRD evidence, i.e., the crystalline nature of the organic element was lost during the synthesis. A similar behavior was detected on XRD patterns and SEM micrographs of a $\mathrm{SiO}_{2}$ gel sample and $\mathrm{SiO}_{2} / \mathrm{PCL}$ gel sample.
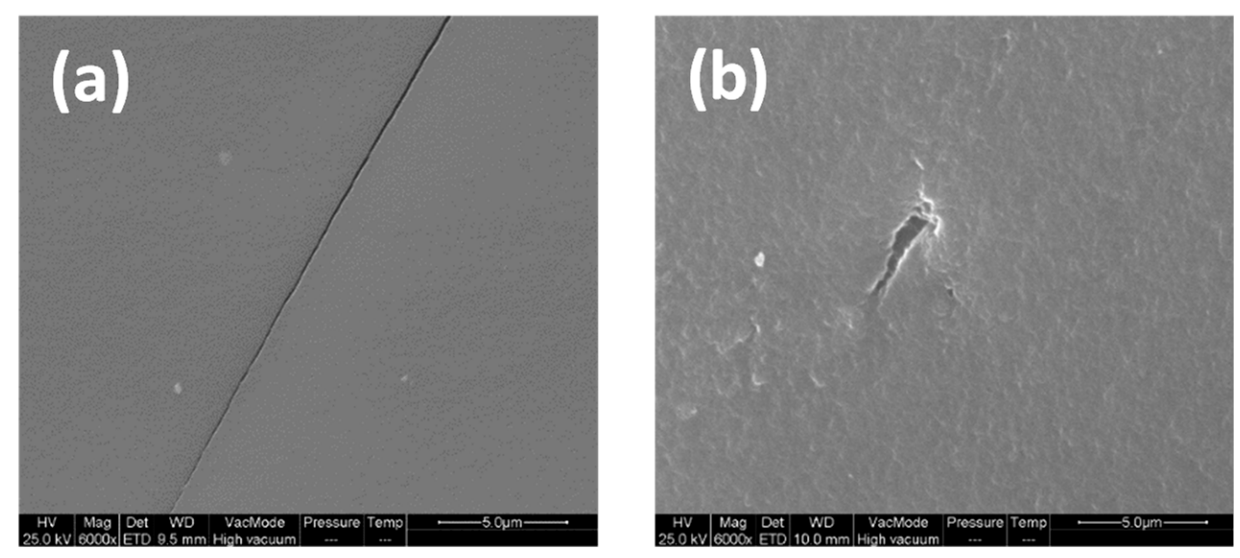

Figure 5. Scanning electron microscopy (SEM) micrograph of (a) $\mathrm{TiO}_{2}$ gel and (b) $\mathrm{TiO}_{2} / \mathrm{PCL}_{6}$ wt.\% gel. 
The degree of mixing of the elements in the hybrid material was investigated with Atomic Force microscopy (AFM). An AFM contact mode image can be measured in the height mode or in the force mode. In force images ( $\mathrm{z}$ range in $\mathrm{nN}$ ), differences appear sharper and richer and the contours of the nanostructure's essentials are clearer. In contrast, height images ( $\mathrm{z}$ range in $\mathrm{nm}$ ) provide a more exact reproduction of the height itself [21]. In this study, the height mode was adopted to estimate the degree of homogeneity of the hybrid materials. AFM topographic images of $\mathrm{SiO}_{2} / \mathrm{PCL}$ and $\mathrm{TiO}_{2} / \mathrm{PCL}$ gel samples are shown in Figure 6, where it can be observed that the average domain size is less than 130 and $40 \mathrm{~nm}$. This answer confirms that the synthesized $\mathrm{SiO}_{2} / \mathrm{PCL}$ and $\mathrm{TiO}_{2} / \mathrm{PCL}$ gels can intrinsically be organic/inorganic hybrid materials [22].

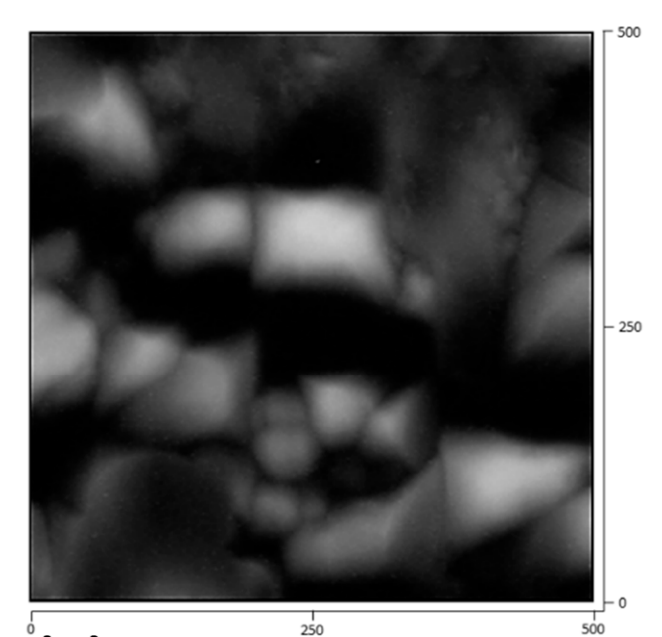

(a)

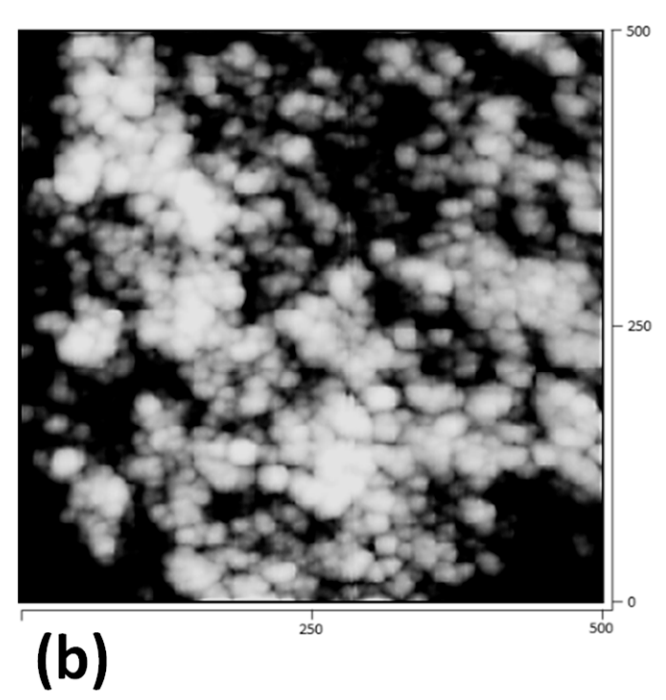

Figure 6. AFM images showing the microstructure of (a) $\mathrm{SiO}_{2} / \mathrm{PCL}_{6}$ wt.\% gel and (b) $\mathrm{TiO}_{2} / \mathrm{PCL}_{6}$ wt.\% gel. The numbers on the axis are in $\mu \mathrm{m}$ (micrometers).

The bioactivity of the $\mathrm{SiO}_{2} / \mathrm{PCL}$ gel was ascertained by FT-IR measurements on a sample soaked in simulated body fluid for 7, 14 and 21 days as shown in Figure 7. The formation of a hydroxyapatite deposit was recognized by the appearance of the 587 and $550 \mathrm{~cm}^{-1}$ bands generally assigned to P-O stretching [23]. After soaking for 7 days, the splitting of the $580 \mathrm{~cm}^{-1}$ band into two others at 587 and at $550 \mathrm{~cm}^{-1}$ can be ascribed to the shape of crystalline hydroxyapatite [23]. These spectra modifications could be ascribable to the formation of the hydroxyapatite precipitate and, in particular, to the stretching of the hydroxyapatite -OH groups and the vibrations of $\mathrm{PO}_{4}{ }^{3-}$ groups, respectively [24]. Moreover, a slight upshift of the Si-OH band (from $955 \mathrm{~cm}^{-1}$ to $960 \mathrm{~cm}^{-1}$ ) suggested the interaction of the hydroxyapatite layer with the $-\mathrm{OH}$ groups of the silica matrix. Finally, the band at $800 \mathrm{~cm}^{-1}$ can be assigned to the Si-O-Si band vibration among two adjacent tetrahedra characteristic of silica gel [24]. The results obtained are in line with the mechanism of the formation of a hydroxy apatite deposit proposed in the literature [25]. 


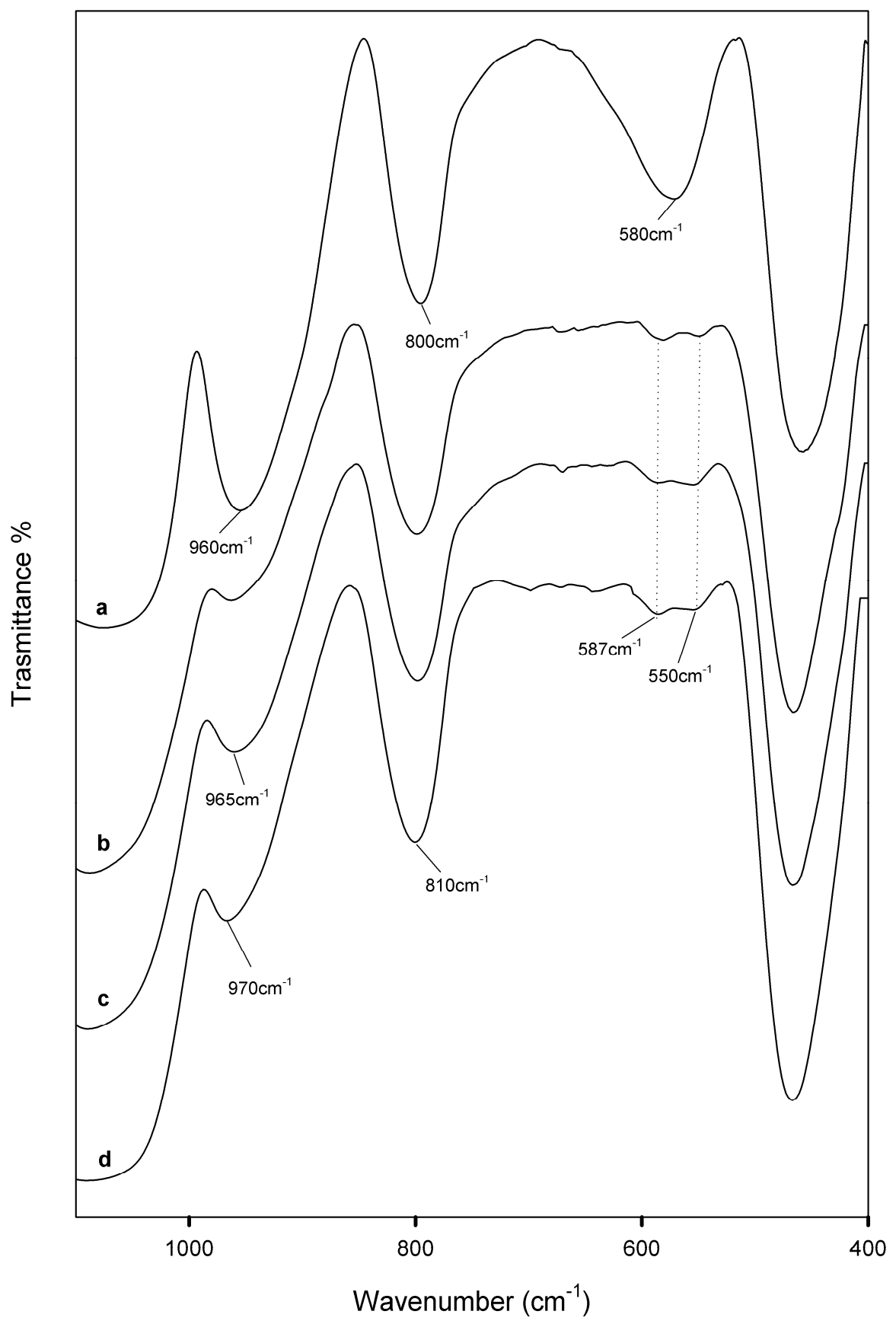

Figure 7. FT-IR spectra of $\mathrm{SiO}_{2} / \mathrm{PCL}$ gel samples after exposure to simulated body fluid (SBF) for different times. (a) not exposed; (b) 7 days; (c) 14 days; (d) 21 days.

Figure 8a shows the SEM micrographs of a $\mathrm{TiO}_{2} / \mathrm{PCL}$ gel sample soaked in $\mathrm{SBF}$ for 21 days. Figure $8 \mathrm{~b}$ confirms that the surface layer observed in the SEM micrographs is composed of calcium phosphate. 


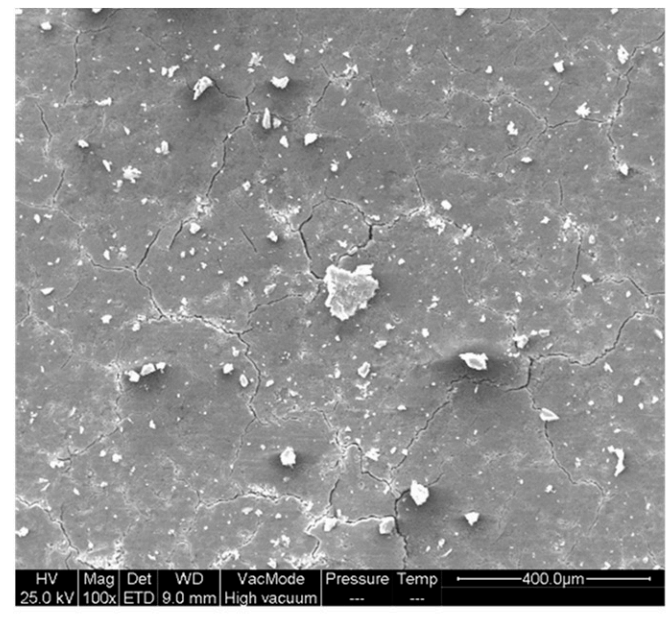

(a)

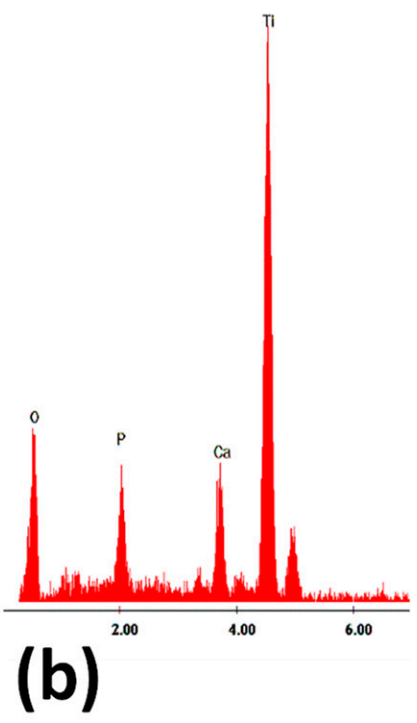

Figure 8. (a) SEM micrographs and (b) EDS of a $\mathrm{TiO}_{2} / \mathrm{PCL}$ gel sample soaked in SBF for 21 days.

Finally, in order to propose the use of the synthetized materials in the biomedical field, as microbial infections can compromise the effectiveness and success of implants, preliminary data from a diffusion assay highlighted that $\mathrm{TiO}_{2} / \mathrm{PCL}_{6}$ wt.\% materials exerted a strong inhibitory effect against Escherichia coli growth (Figure 9). E. coli, a Gram-negative bacterium, being able to easily adapt to changing environmental conditions, is one of the primary causes of Gram-negative orthopedic implant infections. Its resistance to a great variety of antibiotics does not allow for its successful eradication even after treatment. Thus, antimicrobial materials could be advantageous in the biomedical field. Indeed, the significant antimicrobial effect of $\mathrm{TiO}_{2} / \mathrm{PCL}_{6}$ wt.\% could be substantially due to the $\mathrm{TiO}_{2}$ element. In fact, previous findings state that $\mathrm{TiO}_{2}$ nanoparticles found on pathogenic strains of $E$. coli were able to cause little pores to form in bacterial cell walls, leading to increased permeability and cell death [26].

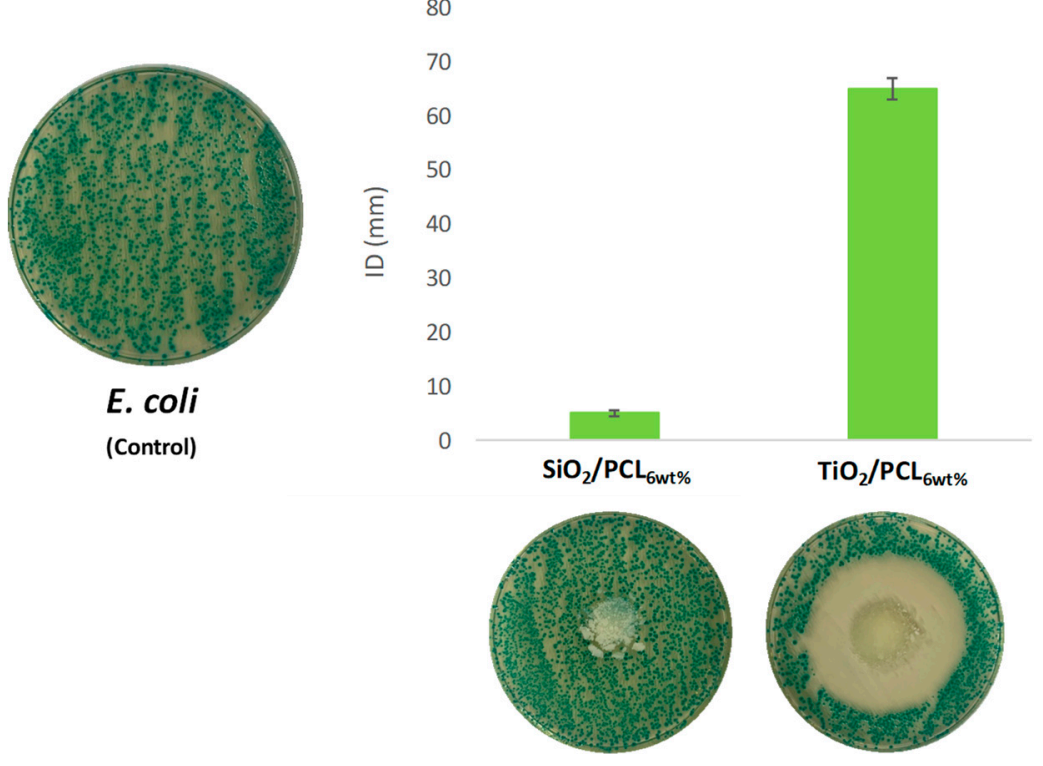

Figure 9. Representative image of Escherichia coli incubated with synthetized hybrid materials and antimicrobial activity reported as inhibitory zone diameter $(\mathrm{mm})$. 


\section{Conclusions}

$\mathrm{MO}_{2} / \mathrm{PCL}$ materials, based on polycaprolactone and silica or titanium metal oxide $(\mathrm{M}=\mathrm{Si}$ or $\mathrm{Ti})$, prepared via the sol-gel process, were found to be organic/inorganic bioactive hybrid materials not altering the gelification and condensation route of the inorganic gel. The polymer (PCL) was crosslinked to the network by hydrogen bonds, as ascertained by FTIR spectra, between the ester groups of the organic polymer and the hydroxyl groups of inorganic matrices. Moreover, the AFM and SEM analyses confirmed that $\mathrm{MO}_{2} / \mathrm{PCL}$ can be considered to be homogenous organic/inorganic hybrid materials because the average domains are less than $400 \mathrm{~nm}$ in size. Finally, the bioactivity of the PCL/MO $/ \mathrm{MO}_{2}$ materials was ascertained by the formation of a layer of hydroxyapatite on the surface when samples were soaked in SBF, as shown in SEM micrographs and related EDS and detected in FTIR spectra. Although further investigations are required for evaluating the mechanical properties of the synthesized hybrid materials, these findings provide initial evidence of the strong antimicrobial effect of the $\mathrm{TiO}_{2} / \mathrm{PCL}$ hybrid and its potential for favorable use.

Author Contributions: Conceptualization, M.C.; methodology, S.P. and M.C.; software, C.L.; validation, M.C., C.L. and formal analysis, S.P. and M.C.; investigation, M.C.; resources, C.L.; data curation, M.C.; writing-original draft preparation, M.C. and C.L.; writing-review and editing, M.C.; visualization, C.L.; supervision, M.C. All authors have read and agreed to the published version of the manuscript.

Funding: This research received no external funding.

Acknowledgments: The authors thank the Ecoricerche srl company for making the microbiology laboratories and materials used for experiments available.

Conflicts of Interest: The authors declare no conflicts of interest.

\section{References}

1. Joshua, D.Y.; Damron, M.; Tang, G.; Zheng, H.; Chu, C.-J.; Osborne, J.H. Inorganic/organic hybrid coatings for aircraft aluminum alloy substrates. Prog. Org. Coat. 2001, 41, 226-232. [CrossRef]

2. Zvonkina, I.J.; Soucek, M.D. Inorganic-organic hybrid coatings: Common and new approaches. Curr. Opin. Chem. Eng. 2016, 11, 123-127. [CrossRef]

3. Figueira, R.B.; Silva, C.J.R.; Petra, E.V. Organic-inorganic hybrid sol-gel coatings for metal corrosion protection: A review of recent progress. J. Coat. Technol. Res. 2015, 12, 1-35. [CrossRef]

4. Klukowska, A.; Posset, U.; Schottner, G.; Wis, M.L.; Salemi-Delvaux, C.; Malatesta, V. Photochromic hybrid sol-gel coatings: Preparation, properties, and applications. Mater. Sci. 2002, 20, 95-104.

5. Samuneva, B.; Djambaski, P.; Kashchieva, E.; Chernev, G.; Kabaivanova, L.; Emanuilova, E.; Salvado, I.M.M.; Fernandes, M.H.V.; Wu, A. Sol-gel synthesis and structure of silica hybrid biomaterials. J. Non Cryst. Solids 2008, 354, 733-740. [CrossRef]

6. Sanchez, C.; Ribot, F. Design of hybrid organic-inorganic materials synthesized via sol-gel chemistry. New J. Chem. 1994, 18, 1007-1047.

7. Catauro, M.; Bollino, F.; Papale, F.; Marciano, S.; Pacifico, S. $\mathrm{TiO}_{2} / \mathrm{PCL}$ hybrid materials synthesized via sol-gel technique for biomedical applications. Mater. Sci. Eng. C 2015, 47, 135-141. [CrossRef] [PubMed]

8. Wei, Y.; Jin, D.; Brennan, D.J.; Rivera, D.N.; Zhuang, Q.; DiNardo, N.J.; Qiu, K. Atomic force microscopy study of organicâ^’inorganic hybrid materials. Chem. Mater. 1998, 10, 769-772. [CrossRef]

9. Catauro, M.; Tranquillo, E.; Barrino, F.; Blanco, I.; Dal Poggetto, F.; Naviglio, D. Drug release of hybrid materials containing Fe (II) citrate synthesized by sol-gel technique. Materials 2018, 11, 2270. [CrossRef] [PubMed]

10. Brinker, C.J.; Scherer, G.W. Sol-gel Science: The Physics and Chemistry of Sol-Gel Processing; Elsevier, Inc.: Amsterdam, The Netherlands, 2013; ISBN 9780080571034.

11. Catauro, M.; Bollino, F.; Mozzati, M.C.; Ferrara, C.; Mustarelli, P. Structure and magnetic properties of $\mathrm{SiO}_{2} / \mathrm{PCL}$ novel sol-gel organic-inorganic hybrid materials. J. Solid State Chem. 2013, 203, 92-99. [CrossRef]

12. Tranquillo, E.; Barrino, F.; Dal Poggetto, G.; Blanco, I. Sol-Gel Synthesis of Silica-Based Materials with Different Percentages of PEG or PCL and High Chlorogenic Acid Content. Materials 2019, 12, 155. [CrossRef] [PubMed] 
13. David, I.A.; Scherer, G.W. An organic/inorganic single-phase composite. Chem. Mater. 1995, 7, $1957-1967$. [CrossRef]

14. Kokubo, T.; Takadama, H. How useful is SBF in predicting in vivo bone bioactivity? Biomaterials 2006, 27, 2907-2915. [CrossRef] [PubMed]

15. Catauro, M.; Barrino, F.; Dal Poggetto, G.; Pacifico, F.; Piccolella, S.; Pacifico, S. Chlorogenic acid/PEG-based organic-inorganic hybrids: A versatile sol-gel synthesis route for new bioactive. Mater. Sci. Eng. C 2019, 100, 837-844. [CrossRef] [PubMed]

16. Catauro, M.; Tranquillo, E.; Dal Poggetto, G.; Pasquali, M.; Dell’Era, A.; Vecchio Ciprioti, S. Influence of the heat treatment on the particles size and on the crystalline phase of $\mathrm{TiO}_{2}$ synthesized by the sol-gel method. Materials 2018, 11, 2364. [CrossRef]

17. Kokubo, T.; Matsushita, T.; Takadama, H.; Kizuki, T. Development of bioactive materials based on surface chemistry. J. Eur. Ceram. Soc. 2009, 29, 1267-1274. [CrossRef]

18. Yang, B.; Uchida, M.; Kim, H.M.; Zhang, X.; Kokubo, T. Preparation of bioactive titanium metal via anodic oxidation treatment. Biomaterials 2004, 25, 1003-1010. [CrossRef]

19. Catauro, M.; Barrino, F.; Dal Poggetto, G.; Crescente, G.; Piccolella, S.; Pacifico, S. Chlorogenic Acid Entrapped in Hybrid Materials with High PEG Content: A Strategy to Obtain Antioxidant Functionalized Biomaterials? Materials 2019, 12, 148. [CrossRef]

20. Blanco, I.; Abate, L.; Bottino, F.A.; Bottino, P. Synthesis, characterization and thermal stability of new dumbbell-shaped isobutyl-substituted POSSs linked by aromatic bridges. J. Therm. Anal. Calorim. 2014, 117, 243-250. [CrossRef]

21. Rädlein, E.; Frischat, G.H. Atomic force microscopy as a tool to correlate nanostructure to properties of glasses. J. Non Cryst. Solids 1997, 222, 69-82. [CrossRef]

22. Nguyena, K.; Garcia, A.; Sanic, M.-A.; Diaza, D.; Dubeyd, V.; Claytona, D.; Dal Poggetto, G.; Corneliuse, F.; Paynea, R.J.; Separovic, F.; et al. Interaction of N-terminal peptide analogues of the $\mathrm{Na}+, \mathrm{K}+-\mathrm{ATPase}$ with membranes. BBA-Biomembr. 2018, 1860, 1282-1291. [CrossRef] [PubMed]

23. Wang, D.S.; Pantano, C.G. Surface chemistry of multielement silicate gels. J. Non Cryst. Solids 1992, 147, 115-122. [CrossRef]

24. Kokubo, T.; Ito, S.; Huang, Z.T.; Hayashi, T.; Sakka, S.; Kitsugi, T.; Yamamuro, T. Ca, P-rich layer formed on high-strength bioactive glass-ceramic A-W. J. Biomed. Mater. Res. 1990, 24, 331-343. [CrossRef] [PubMed]

25. Kokubo, T.; Kushitani, H.; Sakka, S.; Kitsugi, T.; Yamamuro, T. Solutions able to reproduce in vivo surface-structure changes in bioactive glass-ceramic A-W3. J. Biomed. Mater. Res. 1990, 24, 721-734. [CrossRef] [PubMed]

26. Mantravadi, H.B. Effectivity of titanium oxide based nano particles on E. coli from clinical samples. J. Clin. Diagn. Res. 2017, 11, DC37-DC40. [CrossRef] [PubMed] 